\title{
DOSE DE EXPOSIÇÃO RADIOMÉTRICA DE GRANITOS DO ESTADO DE RONDÔNIA, BRASIL
}

\author{
Daniel Marcos Bonotto ${ }^{1}$, Washington Barbosa Leite Júnior ${ }^{1}$, Bruno Leonelo Payolla², \\ Jorge da Silva Bettencourt ${ }^{3}$ e Ene Glória da Silveira ${ }^{4}$
}

Recebido em 27 novembro, 2008 / Aceito em 14 setembro, 2009

Received on November 27, 2008 / Accepted on September 14, 2009

\begin{abstract}
This work evaluated the activity concentration of the radioelements $\mathrm{K}, \mathrm{eU}$ and eTh in samples of granites from Rondônia State, Brazil. The statistical analysis of the data indicated that they fit lognormal distributions. The modal values correspond to about $11 \%$ for $\mathrm{K}, 29 \mathrm{ppm}$ for eU and $85 \mathrm{ppm}$ for eTh. Direct significant correlations were found among the concentrations of the three radioelements, i.e. $r=0.71$ (between $\mathrm{K}$ and $\mathrm{eU}$ ), $r=0.72$ (between $\mathrm{K}$ and eTh), and $r=0.72$ (between eU and eTh), suggesting congruency of their accumulation in minerals occurring in the rocks analyzed. The activity concentration data allowed estimate the absorbed dose rate in air at $1 \mathrm{~m}$ above the ground, which also fits a lognormal distribution characterized by a mode of $2.7 \mathrm{mSv} / \mathrm{y}$ that is slightly higher than the average worldwide exposure of $2.4 \mathrm{mSv} / \mathrm{y}$. The results obtained also allowed evaluate if the granites analyzed are radiometrically suitable as building and ornamental materials.
\end{abstract}

Keywords: radioactivity, gamma exposure rate, granites.

RESUMO. Este trabalho avaliou a concentração dos radioelementos $\mathrm{K}$, eU e eTh em amostras de granitos do Estado de Rondônia, Brasil. A análise estatística dos dados obtidos indicou que eles seguem distribuições lognormais. Os valores modais encontrados correspondem a cerca de $11 \%$ para K, 29 ppm para eU e 85 ppm para eTh. Correlações diretas significativas foram determinadas entre as concentrações dos três radioelementos, isto é, $r=0,71$ (entre $\mathrm{K}$ e eU), $\mathrm{r}=0,72$ (entre K e eTh) e r $=0,72$ (entre eU e eTh), sugerindo que são congruentes os processos de seu acúmulo nos minerais das rochas analisadas. Os dados de concentração permitiram estimar a taxa de dose absorvida de radiação no ar acima de $1 \mathrm{~m}$ do nível do terreno, a qual também segue uma distribuição lognormal, com valor modal de 2,7 mSv/ano, que é ligeiramente superior à média global de 2,4 mSv/ano. Os resultados obtidos também permitiram avaliar, do ponto de vista radiométrico, se os granitos analisados são adequados para emprego como revestimento em construção civil.

Palavras-chave: radioatividade, dose de exposição gama, granitos.

\footnotetext{
${ }_{1}$ Instituto de Geociências e Ciências Exatas (IGCE)/UNESP/Rio Claro, Avenida 24-A, 1515, Cx. Postal 178, Bela Vista, 13506-900 Rio Claro, SP, Brasil. Tel.: (19) 3526-2809-E-mails: danielbonotto@yahoo.com.br; wleite@rc.unesp.br ${ }^{2}$ Centrais Elétricas do Norte do Brasil S.A., ELETRONORTE, SCN Quadra 6, Conjunto A, Edifício Venâncio 3000, Bloco C, Sala 412, Asa Norte, 70718-900 Brasília, DF, Brasil. Tel.: (61) 3429-6157 - E-mail: bruno@eln.gov.br 3 Instituto de Geociências (IG), USP, Rua do Lago, 562, Cidade Universitária, 05508-080 São Paulo, SP, Brasil. Tel.: (11) 3091-4205 - E-mail: jsbetten@usp.br ${ }^{4}$ Fundação Universidade Federal de Rondônia, UNIR, Avenida Presidente Dutra, 2965, Centro, 78900-500 Porto Velho, RO, Brasil. Tel.: (69) 2182-2000 - E-mail: ene_gloria@yahoo.com.br
} 


\section{INTRODUÇÃo}

Estudos envolvendo a distribuição e a intensidade da radioatividade das rochas são de grande importância em Geofísica e Geocronologia, uma vez que encontram várias aplicações, por exemplo, seleção de material rochoso para a datação geológica absoluta, cálculo da produção de calor no interior da Terra, busca de depósitos de minerais radioativos, apoio ao mapeamento geológico, entre outras. Medidas das propriedades radioativas dos materiais de ocorrência natural têm indicado que diferentes níveis de radioatividade estão presentes em todas as rochas e minerais. Os principais radioelementos de ocorrência significativa no material crustal da Terra são 0 potássio, 0 urânio e 0 tório. № princípio atribuía-se a radioatividade principalmente à presença de traços de urânio, tório e seus produtos de decaimento, porém, investigações posteriores indicaram que 0 isótopo de potássio ${ }^{40} \mathrm{~K}$ também contribui significativamente com a radioatividade natural (Sharma, 1986).

$0^{40} \mathrm{~K}$ é 0 isótopo radioativo do potássio de ocorrência natural, constituindo cerca de $0,0117 \%$ do total de potássio presente na natureza. Sua meia vida é de 1,3 $\times 10^{9}$ anos. Aproximadamente $89 \%$ dos átomos de ${ }^{40} \mathrm{~K}$ decaem por emissão de uma partícula $\beta^{-}$para formar átomos de ${ }^{40} \mathrm{Ca}$, enquanto que os $11 \%$ restantes desintegram-se por captura eletrônica para formar átomos de ${ }^{40} \mathrm{Ar}$, com emissão de um fóton gama de energia 1,46 MeV (Dalrymple \& Lanphere, 1969).

0 urânio natural compreende três isótopos: ${ }^{238} \mathrm{U},{ }^{235} \mathrm{U}$ e ${ }^{234} \mathrm{U}$. Esses isótopos correspondem, respectivamente a 99,2743\%, 0,72\% e 0,0057\% da abundância do elemento (Osmond \& Cowart, 1976). 0 s isótopos ${ }^{238} \mathrm{U}$ e ${ }^{235} \mathrm{U}$ dão origem às séries de decaimento do urânio e do actínio, respectivamente, onde seus descendentes apresentam meias-vidas que variam de frações de segundo a milhares de anos. As duas séries de decaimento finalizam no elemento estável chumbo, sendo que $0{ }^{235} \mathrm{U}$, após 11 desintegrações (7 do tipo $\alpha$ e 4 do tipo $\beta^{-}$) origina $0{ }^{207} \mathrm{~Pb}$, e que $0^{238} \mathrm{U}$, após 14 desintegrações ( 8 do tipo $\alpha$ e 6 do tipo $\beta^{-}$) origina $0{ }^{206} \mathrm{~Pb} .0{ }^{234} \mathrm{U}$ é um nuclídeo radiogênico, pertencente à série do ${ }^{238} \mathrm{U}$ (Ivanovich \& Harmon, 1992).

0 tório também é um elemento instável, sendo $0{ }^{232} \mathrm{Th}$ o precursor da série natural de decaimento que após 12 desintegrações ( 7 do tipo $\alpha$ e 5 do tipo $\beta^{-}$) origina $0{ }^{208} \mathrm{~Pb}$. Na mesma série ocorre outro isótopo natural de tório, $0^{228} \mathrm{Th}$.

Os granitos constituem fontes potenciais para metais raros, nobres e base, destacando-se, dentre outros, jazimentos de urânio e tório. Dessa forma, programas de levantamento gamaespectrométrico aeroportado envolvendo os radioelementos $\mathrm{K}$, eU e eTh têm tido boa aplicabilidade na prospecção de depósitos minerais em granitos. Trabalhos efetuados em outros continen- tes têm demonstrado a aplicabilidade da gamaespectrometria, diagnosticando que padrões anômalos para a razão U/Th podem associar-se a granitos potencialmente mineralizados a wolframita e cassiterita, e que anomalias Th/K são obtidas em skarnitos mineralizados (Chiodi Filho, 1997).

Por outro lado, o conhecimento da dose de exposição radiométrica das rochas têm sido relevante para a avaliação da contribuição da radioatividade natural devido aos radionuclídeos presentes, permitindo gerar parâmetros que indicam a viabilidade de sua utilização como materiais ornamentais, de revestimento e para a construção civil. A exportação de granitos ornamentais do Brasil constitui uma importante atividade econômica no país, que é um grande exportador destes materiais (ABIROCHAS, 2008). No geral, os catálogos que têm sido produzidos para a descrição das características das rochas destinadas à comercialização apresentam sua coloração dominante, classificação petrográfica e principais índices físicos, sem haver, contudo, referência a qualquer nível de radioatividade (ABIROCHAS, 2008), que é um parâmetro que têm se constituído em barreira não alfandegária por parte de alguns paises importadores de granitos ornamentais do Brasil. Alguns estudos já têm sido realizados no Brasil visando caracterizar a radioatividade natural em rochas ornamentais (Salas et al., 2003; Moura et al., 2005; Anjos et al., 2005), porém, a maioria das amostras analisadas provém dos estados do Espírito Santo e Minas Gerais, cuja produção corresponde a quase $80 \%$ de todo o material destinado à exportação.

Uma vez que projeções futuras indicam a possibilidade de expansão do mercado de rochas ornamentais, é importante avaliar a potencialidade de utilização de granitos provenientes de outros estados brasileiros. Como a demanda por estudos radiométricos têm crescido no setor de rochas ornamentais, este trabalho descreve a avaliação da concentração dos radioelementos K, eU e eTh em granitos do Estado de Rondônia, Brasil, que ainda é um pequeno produtor desses materiais. Os dados de concentração permitiram estimar a taxa de dose absorvida de radiação no ar acima de $1 \mathrm{~m}$ do nível do terreno, bem como avaliar, do ponto de vista radiométrico, se os granitos analisados são adequados para emprego como revestimento em construção civil.

\section{ASPECTOS GEOLÓGICOS DA ÁREA DE ESTUDO}

A área de estudo está situada no Estado de Rondônia, na porção sudoeste do Cráton Amazônico (Almeida, 1978) e inclui rochas pré-cambrianas das províncias geocronológicas RondôniaJuruena (1.810-1.520 Ma) e Sunsás (1.450-990 Ma) (Santos, 2003). Rochas paleozóicas e mesozóicas estão presentes na Bacia dos Parecis ao sul e coberturas sedimentares cenozóicas continentais, em parte pertencentes aos sistemas fluviais dos 

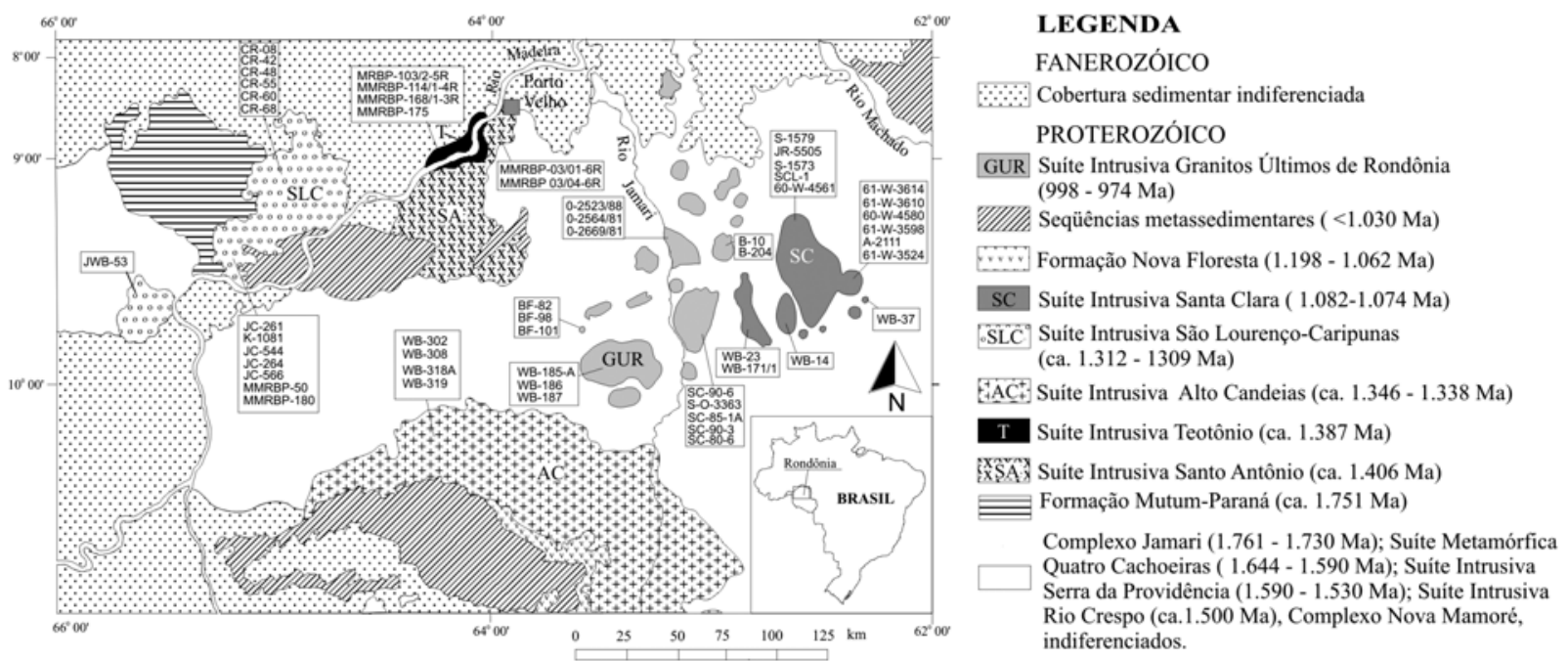

Figura 1 - Mapa geológico simplificado da área de estudo no Estado de Rondônia, Brasil, e localização dos pontos de amostragem dos granitos para a análise dos radioelementos naturais K, eU e eTh (modificado de Leite Júnior, 2002).

rios Guaporé, Mamoré e Madeira, ocorrem nas porções norte, noroeste e sudoeste da área sobre unidades litológicas précambrianas (Quadros \& Rizzotto, 2007) (Fig. 1).

As rochas pré-cambrianas deformadas constituem 0 embasamento cristalino dos granitos objetos desse trabalho. Essas rochas são incluídas nas seguintes unidades litoestratigráficas, não diferenciadas na Figura 1, com exceção da Formação MutumParaná: Complexo Jamari, Suíte Metamórfica Quatro Cachoeiras, Suíte Intrusiva Serra da Providência, Suíte Intrusiva Rio Crespo e Complexo Nova Mamoré (Quadros \& Rizzotto, 2007). 0 Complexo Jamari (1.761-1.730 Ma) é a unidade mais antiga e inclui ortognaisses tonalíticos e quartzo-dioríticos, com intercalações subordinadas de ortognaisses enderbíticos, gnaisses calcissilicáticos e anfibolitos. A Formação Mutum-Paraná (ca. 1.751 Ma) é composta por filitos, ardósias, metargilitos, metarenitos arcosianos, quartzitos, metacherts e metatufos, além de quartzo-metarenitos e metassiltitos. A Suíte Metamórfica Quatro Cachoeira (1.644-1.590 Ma) compreende paragnaisses pelíticos e calcissilicáticos de alto grau metamórfico, com intensidade variável de migmatização. A Suíte Intrusiva Serra da Providência (1.590$1.530 \mathrm{Ma}$ ) é constituída por granitos, charnockitos e quartzomangeritos porfiríticos deformados (augengnaisses e milonitos bandados), ou não, e subordinadamente gabros. A Suíte Intrusiva Rio Crespo (ca. $1.500 \mathrm{Ma}$ ) inclui ortognaisses finos bandados, com composição granítica e charnockítica, e anfibolitos em termos mais subordinados e o Complexo Nova Mamoré compreende rochas paraderivadas representadas por gnaisses, granofels e xistos.
Os granitos da Suíte Intrusiva Santo Antônio (ca. $1406 \mathrm{Ma)}$ aparecem na região da cachoeira homônima no rio Madeira, próximo a Porto Velho (Fig. 1). Incluem principalmente sienogranitos e monzogranitos eqüigranulares e ineqüigranulares seriados, com freqüentes texturas rapakivi e anti-rapakivi (Payolla, 1994). Já a Suíte Intrusiva Teotônio (ca. $1.387 \mathrm{Ma)} \mathrm{ocorre} \mathrm{no}$ rio Madeira entre as cachoeiras Teotônio e Morrinhos (Fig. 1). Compreende álcali-feldspato granitos, sienogranitos e quartzosienitos, além de diques de álcali-feldspato sienitos, monzogranitos, monzonitos, monzodioritos e dioritos (Payolla, 1994).

Os granitos da Suíte Intrusiva Alto Candeias (1.346$1.338 \mathrm{Ma}$ ) constituem um batólito na porção sul da área, na região dos altos cursos dos rios Jamari, Candeias e Jaciparaná (Fig. 1). São monzogranitos com texturas porfiríticas, piterlíticas e eqüigranulares associados com quantidades menores de charnockitos e sienitos, principalmente (Bettencourt et al., 1999). A Suíte Intrusiva São Lourenço-Caripunas (1.312-1.309 Ma) está representada nos maciços Caripunas, São Lourenço e Abunã na parte noroeste da área, entre os estados de Rondônia e Amazonas (Fig. 1). Inclui dominantemente sienogranitos porfiríticos, piterlíticos, wiborgíticos e eqüigranulares, associados com álcalifeldspato granitos, quartzo-sienitos e riolitos pórfiros (Bettencourt \& Kaedei, 1984; Bettencourt et al., 1997, 1999).

A Suíte Intrusiva Santa Clara (1.082-1.074 Ma) está exposta em vários maciços na parte centro-leste da área (Fig. 1). É constituída por monzogranitos e sienogranitos porfiríticos, com álcalifeldspato granitos, álcali-feldspato sienitos, traquitos e riolitos em termos mais subordinados (Leite Júnior, 2002). A Suíte In- 
trusiva Granitos Últimos de Rondônia (998-974 Ma) se distribui também em vários maciços, mas ao longo de uma faixa de direção geral NNE na porção centro-norte da área (Fig. 1). É composta por sienogranitos e álcali-feldspato granitos, associados com quantidades menores de álcali-feldspato sienitos, traquitos e riolitos (Bettencourt et al., 1997, 1999).

\section{AMOSTRAGEM}

Cinquenta e cinco amostras foram coletadas em seis unidades litoestratigráficas que ocorrem na parte setentrional do Estado de Rondônia, que são: suítes intrusivas Santo Antônio, Teotônio, Alto Candeias, São Lourenço-Caripunas, Santa Clara e Granitos Últimos de Rondônia (Fig. 1). A amostragem foi realizada com base na representatividade dos tipos petrográficos conhecidos em cada unidade.

As amostras das suítes intrusivas Santo Antônio e Teotônio foram coletadas nas regiões das cachoeiras homônimas, segundo Payolla (1994). Na Suíte Intrusiva Alto Candeias, ainda pouco conhecida, a amostragem foi realizada ao longo da BR-421, entre os municípios de Montenegro e Campo Novo de Rondônia, assim como no município de Buritis. Na Suíte Intrusiva São Lourenço-Caripunas as amostras foram coletadas nos maciços São Lourenço, Caripunas e Abunã, de acordo com Bettencourt \& Kaedei (1984) e Bettencourt et al. (1991). Na Suíte Intrusiva Santa Clara a amostragem foi realizada nos maciços Manteiga, Oriente Velho, Santa Clara, Oriente Novo e Primavera, segundo Leite Júnior (2002). Finalmente, as amostras da Suíte Intrusiva Granitos Últimos de Rondônia foram coletadas nos maciços Massangana, Palanqueta, São Carlos, Caritianas e Pedra Branca, segundo Bettencourt et al. (1991) e Leite Júnior et al. (2005). A Tabela 1 sumariza os tipos petrográficos das amostras coletadas em cada suíte.

Uma vez transportadas ao laboratório, as amostras foram submetidas a britagem, moagem e pulverização até 200 mesh. Para a determinação da radioatividade natural devido ao $\mathrm{K}$, ao eU e ao eTh, uma alíquota de cada amostra foi inicialmente pesada, acondicionada em caixa de alumínio (62 mm de diâmetro e 23 mm de altura) e selada para obter, em cerca de quatro semanas, equilíbrio radioativo entre $0{ }^{222} \mathrm{Rn}$, seus descendentes de curta meia-vida e $0{ }^{226} \mathrm{Ra}$ na série de decaimento do ${ }^{238} \mathrm{U}$ (Chiozzi et al., 2000).

\section{PROCEDIMENTO ANALÍTICO}

As amostras coletadas foram analisadas quanto aos radioelementos naturais por intermédio de espectrometria gama com detector de cintilação de Nal(TI). Este método tem provado ser de fácil uso, altamente sensível e rápido, sendo aplicado rotineiramente com sucesso em inúmeras investigações geofísicas. 0 espectrômetro de raios gama é formado de um sensor gama - cristal de Nal(TI) - e dispositivos eletrônicos que separam o feixe de radiação incidente no cristal em distintos componentes energéticos. A preparação das amostras para leituras por espectrometria de raios gama é simples, não requer digestão, não necessita de spikes, podendo ser analisados simultaneamente vários radionuclídeos de interesse.

0 espectrômetro gama utilizado está instalado no LABIDRO (Laboratório de Isótopos e Hidroquímica) do Departamento de Petrologia e Metalogenia (DPM) da UNESP de Rio Claro. 0 cristal de Nal(TI) possui dimensões de $2^{\prime \prime} \times 2^{\prime \prime}$, ocorrendo vários processos (efeito fotoelétrico, espalhamento Compton, produção de pares, entre outros) por ocasião da interação da radiação gama com 0 cristal (Ward, 1981). Pulsos de pequena amplitude são produzidos no ânodo de uma válvula fotomultiplicadora, os quais exibem alturas variáveis que dependem diretamente da energia da radiação; então, são pré-amplificados e dirigidos a um amplificador, onde são conformados para análise no próximo estágio, consistindo em discriminação de acordo com suas alturas por um analisador multicanal de 2048 canais (placa ACE de $2 \mathrm{~K}$ da EG\&G ORTEC, controlada pelo software Maestro II) que fornece espectros relacionados com a energia da radiação gama emitida nas transições nucleares. Integra ainda o sistema espectrométrico uma blindagem de chumbo da EG\&G ORTEC pesando aproximadamente 1 tonelada onde estão inseridos o pré-amplificador e 0 cristal de $\mathrm{Nal}(\mathrm{TI})$ acoplado à válvula fotomultiplicadora, que é polarizada por uma fonte de alta tensão. É nesta blindagem de chumbo que é inserida a amostra acondicionada em recipiente de alumínio.

Na espectrometria gama convencional com detector de cintilação de $\mathrm{Nal}(\mathrm{TI})$, os nuclídeos geralmente mensurados são 0 ${ }^{40} \mathrm{~K}, 0^{214} \mathrm{Bi}$ (da série do ${ }^{238} \mathrm{U}$ ) e o ${ }^{208} \mathrm{TI}$ (da série do ${ }^{232} \mathrm{Th}$ ), sendo os dados inicialmente expressos em taxas de contagem (número de contagens por unidade de tempo). Posteriormente, através de um processo de calibração, os resultados são expressos em termos de concentrações de potássio, equivalentes de urânio e tório, de maneira que as determinações de $U$ e Th por meio da espectrometria gama são indicadas pelo prefixo 'e' (equivalente), ou seja, 'eU' e 'eTh' (Adams \& Gasparini, 1970; Killeen, 1979). Tais determinações baseiam-se na premissa de que existe equilíbrio radioativo entre $0{ }^{238} \mathrm{U}$ e $0{ }^{232} \mathrm{Th}$ e seus descendentes nas respectivas séries de decaimento. As janelas espectrais para as medidas gamaespectrométricas variaram de 1,36 a 1,56 MeV (K), de 1,66 a 1,86 MeV (eU) e de 2,42 a 2,82 MeV (eTh), estando associadas a emissões gama que não se sobrepõem, referentes às seguin- 
Tabela 1 - Tipos petrográficos dos granitos analisados para os radioelementos naturais $\mathrm{K}$, eU e eTh.

\begin{tabular}{|c|c|}
\hline Suíte & Classificação petrográfica (IUGS ${ }^{1}$ ) \\
\hline \multicolumn{2}{|c|}{ Suíte Intrusiva Santo Antônio } \\
\hline MMRBP-03/01-6R & Biotita sienogranito \\
\hline MMRBP 03/04-6R & Biotita monzogranito \\
\hline \multicolumn{2}{|c|}{ Suíte Intrusiva Teotônio } \\
\hline MRBP-103/2-5R & $\begin{array}{l}\text { Faialita-hornblenda-clinopiroxênio álcali-feldspato } \\
\text { quartzo-sienito }{ }^{2}\end{array}$ \\
\hline MMRBP-114/1-4R & Biotita-hornblenda quartzo-sienito ${ }^{2}$ \\
\hline MMRBP-168/1-3R & Clinopiroxênio-hornblenda álcali-feldspato granito \\
\hline MMRBP-175 & Clinopiroxênio-hornblenda álcali-feldspato granito \\
\hline \multicolumn{2}{|c|}{ Suíte Intrusiva Alto Candeias } \\
\hline WB-302 & Biotita-hornblenda monzogranito piterlítico \\
\hline WB-308 & Charnockito porfirítico \\
\hline WB-318A & Biotita-hornblenda monzogranito piterlítico \\
\hline WB-319 & Biotita-hornblenda monzogranito piterlítico \\
\hline \multicolumn{2}{|c|}{ Suíte Intrusiva São Lourenço-Caripunas } \\
\hline \multicolumn{2}{|c|}{ Maciço São Lourenço } \\
\hline JC-261 & Biotita-hornblenda quartzo-sienito porfirítico ${ }^{2}$ \\
\hline K-1081 & Hornblenda-biotita sienogranito porfirítico \\
\hline JC-544 & Biotita sienogranito porfirítico \\
\hline JC-264 & Biotita sienogranito \\
\hline JC-566 & Biotita álcali-feldspato granito \\
\hline MMRBP-50 & Biotita sienogranito \\
\hline MMRBP-180 & Biotita sienogranito porfirítico \\
\hline \multicolumn{2}{|l|}{ Maciço Caripunas } \\
\hline CR-08 & Hornblenda-biotita álcali-feldspato granito \\
\hline CR-42 & Hornblenda-biotita álcali-feldspato granito \\
\hline CR-48 & Hornblenda-biotita sienogranito porfirítica \\
\hline CR-55 & Hornblenda-biotita sienogranito \\
\hline CR-60 & Hornblenda-biotita sienogranito piterlítico \\
\hline CR-68 & Hornblenda-biotita sienogranito piterlítico \\
\hline \multicolumn{2}{|l|}{ Maciço Abunã } \\
\hline JWB-53 & Biotita sienogranito \\
\hline \multicolumn{2}{|c|}{ Suíte Intrusiva Santa Clara } \\
\hline \multicolumn{2}{|l|}{ Maciço Manteiga } \\
\hline WB-23 & Biotita monzogranito porfirítico \\
\hline WB-171/1 & Biotita sienogranito porfirítico \\
\hline \multicolumn{2}{|c|}{ Maciço Oriente Velho } \\
\hline WB-14 & Biotita monzogranito porfirítico \\
\hline
\end{tabular}

\footnotetext{
${ }^{1}$ IUGS = International Union of Geological Sciences $;{ }^{2}$ quartzo-sienito; ${ }^{3}$ sienito.
} 
Tabela 1 (cont.) - Tipos petrográficos dos granitos analisados para os radioelementos naturais K, eU e eTh.

\begin{tabular}{|c|c|}
\hline Suíte & Classificação petrográfica (IUGS ${ }^{1}$ ) \\
\hline \multicolumn{2}{|c|}{ Suíte Intrusiva Santa Clara } \\
\hline \multicolumn{2}{|c|}{ Maciço Santa Clara } \\
\hline S-1579 & Biotita monzogranito porfirítico \\
\hline JR-5505 & Biotita sienogranito porfirítico \\
\hline S-1573 & Biotita sienogranito porfirítico \\
\hline SCL-1 & Biotita sienogranito porfirítico \\
\hline $60-W-4561$ & Hornblenda álcali-feldspato sienito ${ }^{3}$ \\
\hline \multicolumn{2}{|c|}{ Maciço Oriente Novo } \\
\hline $61-W-3614$ & Hornblenda-biotita monzogranito porfirítico \\
\hline $61-W-3610$ & Biotita sienogranito porfirítico \\
\hline $60-W-4580$ & Biotita sienogranito porfirítico \\
\hline $61-W-3598$ & Biotita álcali-feldspato granito \\
\hline A-2111 & Muscovita-biotita micromonzogranito \\
\hline $61-W-3524$ & Zinnwaldita álcali-feldspato granito \\
\hline \multicolumn{2}{|c|}{ Maciço Primavera } \\
\hline WB-37 & Álcali-feldspato granito (alasquito) \\
\hline \multicolumn{2}{|c|}{ Suíte Intrusiva Granitos Últimos de Rondônia } \\
\hline \multicolumn{2}{|c|}{ Maciço Massangana } \\
\hline WB-185-A & Biotita sienogranito porfirítico \\
\hline WB-186 & Biotita sienogranito \\
\hline WB-187 & Biotita sienogranito \\
\hline \multicolumn{2}{|c|}{ Maciço Palanqueta } \\
\hline BF-82 & Biotita sienogranito \\
\hline BF-98 & Topázio-zinnwaldita álcali-feldspato granito pórfiro \\
\hline $\mathrm{BF}-101$ & Topázio-zinnwaldita álcali-feldspato granito \\
\hline \multicolumn{2}{|c|}{ Maciço São Carlos } \\
\hline SC-90-6 & Biotita-hornblenda sienogranito \\
\hline S-0-3363 & Biotita-hornblenda sienogranito \\
\hline SC-85-1A & Hornblenda-biotita sienogranito \\
\hline SC-90-3 & Biotita sienogranito \\
\hline SC-80-6 & Biotita sienogranito \\
\hline \multicolumn{2}{|c|}{ Maciço Caritianas } \\
\hline $0-2523 / 88$ & Biotita sienogranito \\
\hline $0-2564 / 81$ & Biotita sienogranito \\
\hline $0-2669 / 81$ & Biotita sienogranito \\
\hline \multicolumn{2}{|c|}{ Maciço Pedra Branca } \\
\hline $\mathrm{B}-10$ & Biotita monzogranito \\
\hline B-204 & Biotita sienogranito \\
\hline
\end{tabular}

${ }^{1}$ IUGS = International Union of Geological Sciences $;{ }^{2}$ quartzo-sienito; ${ }^{3}$ sienito. 


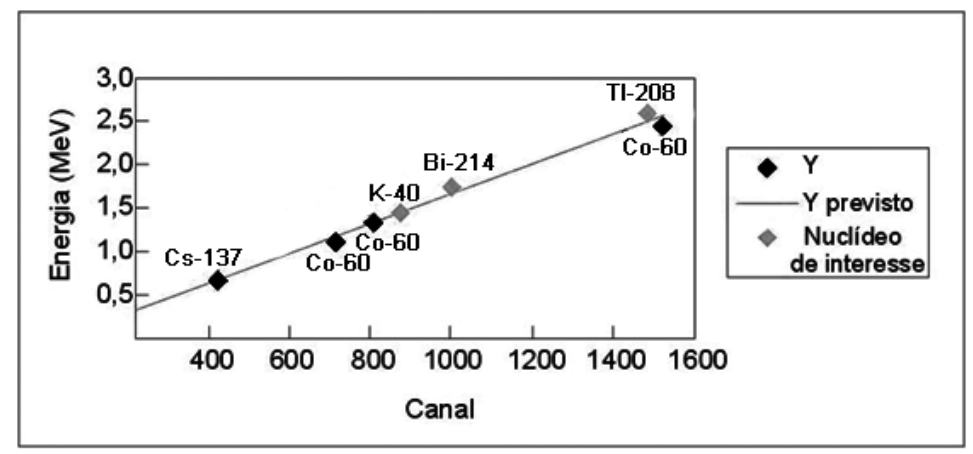

Figura 2 - Calibração em energia do sistema utilizado para as medidas gamaespectrométricas realizadas neste trabalho, segundo Duarte \& Bonotto (2000).

tes energias: $1,46 \mathrm{MeV}\left({ }^{40} \mathrm{~K}\right), 1,76 \mathrm{MeV}\left(\mathrm{eU}={ }^{214} \mathrm{Bi}\right)$ e 2,62 MeV $\left(\mathrm{eTh}={ }^{208} \mathrm{TI}\right)($ Ward, 1981).

Uma fonte monoenergética de ${ }^{137} \mathrm{Cs}(0,661 \mathrm{MeV}$, segundo Ward, 1981) foi empregada para determinar a resolução do sistema gamaespectrométrico utilizado, obtendo-se para o fotopico associado a este radionuclídeo um valor correspondente a 9,5\%, 0 qual é típico para detectores de cintilação de Nal(TI) (Ivanovich \& Harmon, 1992). Esta fonte juntamente com outra de ${ }^{60} \mathrm{Co}$ que exibe fotopicos de energia correspondendo a 1,173, 1,332 e 2,405 MeV (Ward, 1981) foram empregadas para a calibração do sistema em energia, visando a realização das leituras gamaespectrométricas, conforme ilustrado na Figura 2.

Efetuou-se também a calibração do sistema gamaespectrométrico utilizado. Para tanto, foram empregados padrões com concentrações conhecidas dos nuclídeos de interesse. Para 0 urânio, empregaram-se padrões adquiridos junto ao NBL (New Brunswick Laboratory) do U.S. Department of Energy, Argonne, Illinois, consistindo de pechblenda com distintas concentrações, para os quais procedeu-se a determinação da taxa de contagem no fotopico do ${ }^{214} \mathrm{Bi}$. Para o tório, foram utilizados padrões consistindo de areia monazítica também adquiridos do NBL, juntamente com outro padrão confeccionado no LABIDRO a partir de amostra de sedimentos de fundo provenientes do Morro do Ferro (Poços de Caldas, MG); a taxa de contagem no fotopico do ${ }^{208} \mathrm{TI}$ foi determinada para cada padrão utilizado. Para o potássio, tomou-se $\mathrm{KCl}$ (P.A.) puro, correspondente à concentração de $52 \%$ de $\mathrm{K}$, e procedeu-se a mistura e homogeneização com sílica pura, adicionada em diferentes proporções; a taxa de contagem no fotopico do ${ }^{40} \mathrm{~K}$ foi então determinada para cada mistura confeccionada. A partir dos dados obtidos, foram traçadas curvas de calibração da concentração de cada radioelemento ( $\mathrm{K}$ em \%; eU e eTh em ppm) em função da intensidade efetiva (taxa de contagem por massa) associada a cada padrão, conforme descrito por Duarte \& Bonotto (2000).
Para cada radionuclídeo de interesse, foi determinado o nível crítico ( $L c$ ) de detecção, estabelecido por Currie (1968), visando verificar se 0 sinal encontrado realmente correspondeu à detecção de um fotopico, principalmente nos casos de obtenção de baixa taxa de contagem. Uma decisão estatística a posteriori pode ser baseada no nível crítico $(L c)$. Para tanto, foi necessário proceder leituras da radiação de fundo na região dos fotopicos de interesse, isto é, ${ }^{40} \mathrm{~K},{ }^{214} \mathrm{Bi}$ e ${ }^{208} \mathrm{TI}$. As medidas da radiação de fundo nestas regiões foram utilizadas para encontrar o nível crítico $L c$ (em número de contagens) para cada radionuclídeo, a partir da expressão $L c=2,33 \sqrt{N_{B}}$ (Currie, 1968), onde $N_{B}$ corresponde ao número de contagens devido à radiação de fundo. Quando as contagens líquidas em cada fotopico excedem $L c$, considera-se que o radionuclídeo foi caracterizado (detectado) na amostra. Caso isto não ocorra, estabelece-se 0 limite de detecção $L d$, em número de contagens, a partir da equação $L d=2,71+4,61 \sqrt{N_{B}}$ (Currie, 1968). As incertezas dos valores de concentração associados aos fotopicos detectados foram calculadas considerando um desvio padrão e a aplicação do teorema de propagação de erros (Young, 1962).

\section{RESULTADOS E DISCUSSÃO}

\section{Distribuição das concentrações dos radioelementos}

Todas as leituras nas amostras forneceram números de contagens que se situaram acima do nível crítico $L c$, de maneira que não foi necessário determinar 0 limite de detecção $L d$ (Currie, 1968) para nenhuma amostra. As incertezas dos valores de concentração variaram de 0,1 a $24 \%$, onde os maiores valores obtidos referem-se geralmente às amostras com menores teores nos radioelementos, o que se deve à natureza estatística do decaimento radioativo bem como à aplicação do teorema de propagação de erros (Young, 1962). 0 tempo de contagem para as amostras variou de 19 a 52 h., estando ilustrados na Tabela 2 
os resultados obtidos, que corresponderam aos seguintes intervalos de variação: $K=2,9$ a 16,8\%; eU = 4,6 a 88,4 ppm; $\mathrm{eTh}=2,8$ a 166,4 ppm.

A análise estatística dos dados obtidos indica que as concentrações dos radioelementos seguem distribuições lognormais, conforme ilustrado na Figura 3. Os valores modais encontrados correspondem a cerca de $11 \%$ para K, 29 ppm para eU e 85 ppm para eTh. Correlações diretas significativas foram determinadas entre as concentrações dos três radioelementos, isto é, $r=0,71$ (entre $\mathrm{K}$ e eU), $r=0,72$ (entre $\mathrm{K}$ e eTh) e $r=0,72$ (entre eU e eTh) (Fig. 4). Essas correlações sugerem que são congruentes os processos de acúmulo dos três radioelementos nos minerais das rochas analisadas, os quais têm sido amplamente relatados na literatura (Picciotto, 1950; Roubault, 1958; Moreira-Nordemann, 1977; Robb et al., 1990; Scheepers, 2000; El-Naby \& Saleh, 2003; Kumar \& Reddy, 2004). Por exemplo, tem sido possível identificar que nos granitos, o tório e urânio se encontram preferencialmente nos minerais acessórios, permanecendo disseminado nos minerais principais ou fraturas e interstícios entre os cristais, bem como que dentre os minerais constituintes de granitos (quartzo, plagioclásio, ortoclásio, bio- tita, anfibólio, minerais pesados), cerca de 70 a $80 \%$ do teor total de urânio ocorre em biotita e minerais pesados. Além disso, a distribuição de urânio em rochas cristalinas constituídas principalmente de quartzo e feldspato indicou que a biotita detém de 19 a 22\% do teor total de urânio na rocha, enquanto que os minerais pesados (zircão, monazita, apatita, magnetita, ilmenita, riebeckita) entre 61 e $65 \%$ desse teor.

Assim, de uma maneira geral, nas rochas cristalinas, a maior parte do urânio e do tório está incorporada nos minerais acessórios como monazita, alanita, esfeno e zircão, de maneira que esses radioelementos não estão prontamente acessíveis aos processos de dissolução e mineralização secundária (Larsen \& Phair, 1954; Brown \& Silver, 1955; Adams et al. 1959; Gabelman, 1977; Speer et al., 1981; Tieh \& Ledger 1981; Weijden \& Weijden, 1995; Gavshin et al., 1997; Seimbille et al., 1998). Os principais minerais formadores de rochas estão mais susceptíveis aos processos de lixiviação, principalmente durante 0 intemperismo, quando ocorre a alteração das rochas. 0 estudo da distribuição de urânio em rochas ígneas indicou que menos de 1/3 está presente como óxido intersticial ou agregado cripto-cristalino, o qual está disponível aos

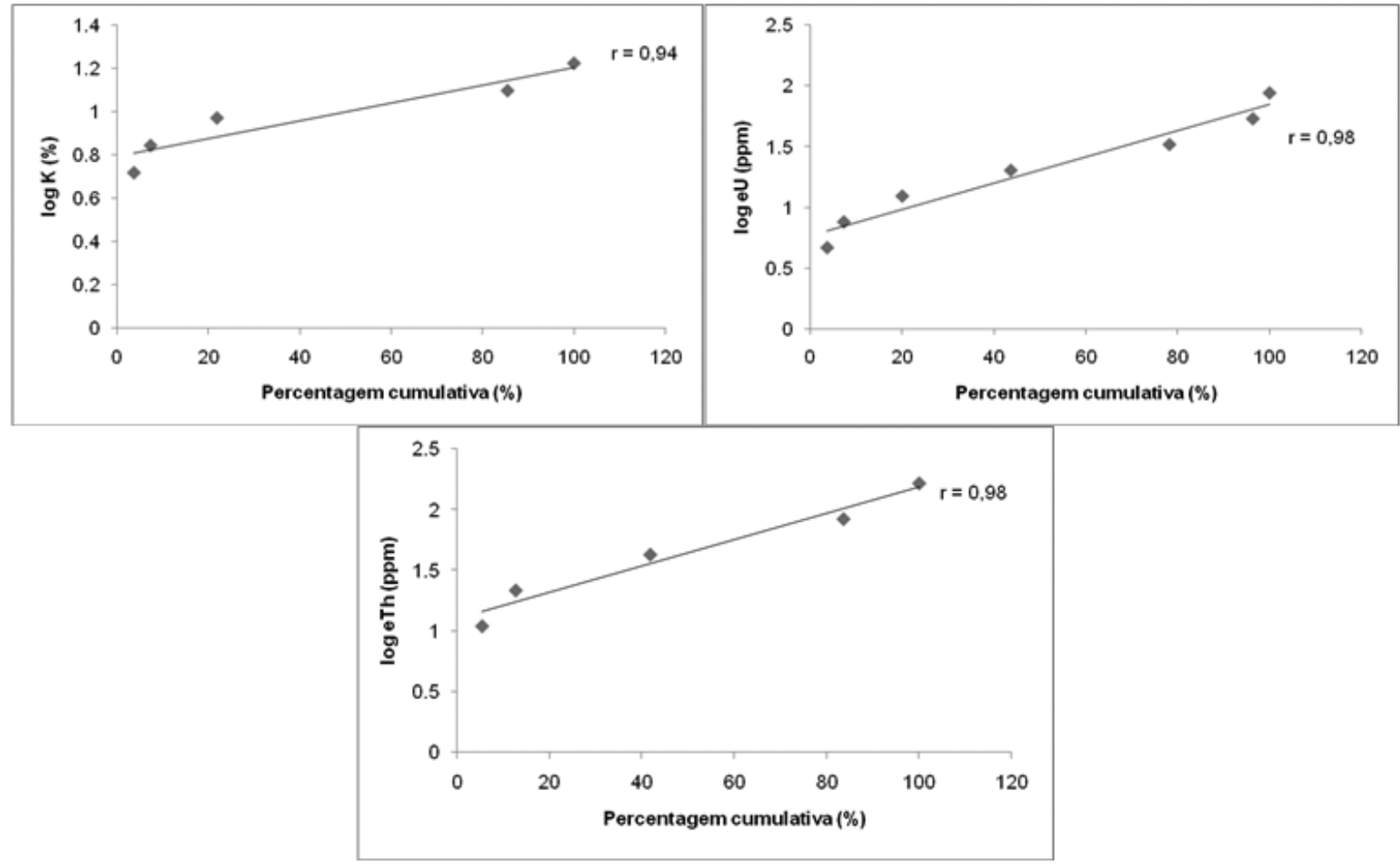

Figura 3 - Distribuição estatística dos dados de concentração dos radioelementos naturais K, eU e eTh nas rochas do Estado de Rondônia. 
Tabela 2 - Resultados obtidos para a concentração dos radioelementos naturais K, eU e eTh nas rochas do Estado de Rondônia analisadas neste trabalho. As incertezas analíticas considerando um desvio padrão variaram de 0,1 a $24 \%$.

\begin{tabular}{|c|c|c|c|c|c|}
\hline Amostra & $\begin{array}{c}\text { Massa } \\
(\mathrm{g})\end{array}$ & $\begin{array}{c}\text { Tempo de } \\
\text { contagem (h) }\end{array}$ & $\begin{array}{c}\mathrm{K} \\
(\%)\end{array}$ & $\begin{array}{c}\mathrm{eU} \\
(\mathrm{ppm})\end{array}$ & $\begin{array}{c}\text { eTh } \\
\text { (ppm) }\end{array}$ \\
\hline \multicolumn{6}{|c|}{ Suíte Intrusiva Santo Antônio } \\
\hline MMRBP-03/01-6R & 34,4 & 23,2 & 12,3 & 39,7 & 72,9 \\
\hline MMRBP 03/04-6R & 34,6 & 24,1 & 14,6 & 56,2 & 74,0 \\
\hline \multicolumn{6}{|c|}{ Suíte Intrusiva Teotônio } \\
\hline MRBP-103/2-5R & 33,9 & 22,1 & 11,3 & 16,4 & 55,0 \\
\hline MMRBP-114/1-4R & 28,8 & 20,5 & 9,7 & 9,2 & 9,6 \\
\hline MMRBP-168/1-3R & 30,4 & 26,7 & 8,6 & 7,6 & 19,9 \\
\hline MMRBP-175 & 27,4 & 24,1 & 11,3 & 14,0 & 38,4 \\
\hline \multicolumn{6}{|c|}{ Suíte Intrusiva Alto Candeias } \\
\hline WB-302 & 31,4 & 29,3 & 11,5 & 15,9 & 52,8 \\
\hline WB-308 & 30,0 & 52,2 & 2,9 & 4,6 & 2,8 \\
\hline WB-318A & 30,1 & 21,6 & 12,0 & 20,0 & 55,1 \\
\hline WB-319 & 32,9 & 23,0 & 12,9 & 22,4 & 71,0 \\
\hline \multicolumn{6}{|c|}{ Suíte Intrusiva São Lourenço-Caripunas } \\
\hline JC-261 & 42,1 & 22,7 & 10,5 & 15,4 & 40,4 \\
\hline K-1081 & 38,3 & 41,8 & 12,5 & 23,6 & 61,3 \\
\hline JC-544 & 27,7 & 31,4 & 13,4 & 28,8 & 80,9 \\
\hline JC-264 & 30,3 & 28,1 & 16,7 & 88,4 & 166,4 \\
\hline JC-566 & 35,5 & 20,3 & 12,4 & 26,0 & 63,0 \\
\hline MMRBP-50 & 30,9 & 24,8 & 11,9 & 23,0 & 35,5 \\
\hline MMRBP-180 & 40,2 & 27,8 & 16,8 & 82,1 & 140,3 \\
\hline CR-08 & 42,0 & 23,3 & 12,4 & 25,3 & 78,7 \\
\hline CR-42 & 38,7 & 22,7 & 16,7 & 54,5 & 140,2 \\
\hline CR-48 & 41,7 & 23,8 & 14,2 & 44,3 & 74,0 \\
\hline CR-55 & 35,6 & 21,6 & 13,2 & 42,4 & 123,4 \\
\hline CR-60 & 28,2 & 23,7 & 11,3 & 27,5 & 47,3 \\
\hline CR-68 & 23,6 & 24,0 & 10,5 & 15,9 & 45,0 \\
\hline JWB-53 & 17,8 & 20,8 & 13,2 & 49,7 & 86,8 \\
\hline \multicolumn{6}{|c|}{ Suíte Intrusiva Santa Clara } \\
\hline WB-23 & 18,3 & 19,3 & 14,4 & 57,4 & 160,8 \\
\hline WB-171/1 & 30,3 & 24,4 & 13,3 & 25,8 & 112,6 \\
\hline WB-14 & 33,1 & 23,2 & 13,2 & 18,3 & 91,8 \\
\hline S-1579 & 9,3 & 23,5 & 14,8 & 31,7 & 101,3 \\
\hline JR-5505 & 12,4 & 45,0 & 15,2 & 47,6 & 140,6 \\
\hline S-1573 & 6,2 & 28,7 & 13,4 & 29,7 & 108,2 \\
\hline SCL-1 & 12,6 & 21,9 & 12,4 & 37,0 & 102,9 \\
\hline $60-W-4561$ & 14,8 & 28,6 & 13,2 & 28,2 & 52,6 \\
\hline 61-W-3614 & 21,4 & 23,3 & 13,1 & 26,5 & 111,3 \\
\hline $61-W-3610$ & 55,2 & 23,8 & 3,0 & 5,3 & 21,8 \\
\hline $60-W-4580$ & 23,4 & 26,9 & 14,8 & 45,7 & 41,1 \\
\hline $61-W-3598$ & 27,3 & 28,4 & 10,9 & 24,5 & 71,1 \\
\hline $\mathrm{A}-2111$ & 19,2 & 24,0 & 12,4 & 34,9 & 37,1 \\
\hline 61-W-3524 & 26,7 & 28,6 & 7,8 & 19,4 & 69,5 \\
\hline WB-37 & 4,3 & 24,4 & 8,7 & 14,3 & 8,7 \\
\hline
\end{tabular}


Tabela 2 (cont.) - Resultados obtidos para a concentração dos radioelementos naturais K, eU e eTh nas rochas do Estado de Rondônia analisadas neste trabalho. As incertezas analíticas considerando um desvio padrão variaram de 0,1 a 24\%.

\begin{tabular}{|c|c|c|c|c|c|}
\hline Amostra & $\begin{array}{c}\text { Massa } \\
(\mathrm{g})\end{array}$ & $\begin{array}{c}\text { Tempo de } \\
\text { contagem (h) }\end{array}$ & $\begin{array}{c}\mathrm{K} \\
(\%)\end{array}$ & $\begin{array}{c}\mathrm{eU} \\
(\mathrm{ppm})\end{array}$ & $\begin{array}{c}\text { eTh } \\
(\mathrm{ppm})\end{array}$ \\
\hline \multicolumn{5}{|c|}{ Suíte Intrusiva Granitos Últimos de Rondônia } \\
\hline WB-185-A & 5,5 & 23,0 & 12,1 & 46,6 & 114,6 \\
\hline WB-186 & 29,6 & 22,7 & 12,1 & 34,4 & 81,4 \\
WB-187 & 30,7 & 22,8 & 13,4 & 31,2 & 96,7 \\
\hline BF-82 & 24,8 & 22,3 & 12,3 & 33,9 & 61,3 \\
\hline BF-98 & 20,0 & 23,7 & 6,6 & 16,5 & 30,3 \\
\hline BF-101 & 9,5 & 24,9 & 10,4 & 51,2 & 19,1 \\
\hline SC-90-6 & 7,7 & 43,8 & 17,8 & 35,5 & 86,5 \\
\hline S-0-3363 & 10,1 & 23,6 & 11,4 & 13,3 & 40,5 \\
\hline SC-85-1A & 11,6 & 23,9 & 11,9 & 16,3 & 39,4 \\
\hline SC-90-3 & 7,4 & 23,9 & 12,6 & 34,4 & 113,1 \\
\hline SC-80-6 & 8,4 & 23,7 & 12,7 & 35,6 & 86,7 \\
\hline $0-2523 / 88$ & 30,0 & 24,3 & 13,6 & 42,9 & 125,6 \\
\hline $0-2564 / 81$ & 35,7 & 22,8 & 10,5 & 27,6 & 85,1 \\
\hline $0-2669 / 81$ & 33,0 & 21,6 & 15,7 & 45,7 & 141,6 \\
\hline B-10 & 31,4 & 24,1 & 14,5 & 34,0 & 126,1 \\
\hline B-204 & 30,9 & 23,7 & 13,9 & 39,2 & 131,7 \\
\hline
\end{tabular}

processos de lixiviação, tendo sido também estimado que de 60 a $85 \%$ do Th e do U nas rochas ígneas está contido nos resistatos, que estão incorporados intactos nos seus derivados sedimentares.

0 tório ocorre predominantemente como um cátion tetravalente, constituindo traço em fosfatos, óxidos e silicatos simples e múltiplos, bem como um elemento principal em minerais como monazita, torianita $\left(\mathrm{ThO}_{2}\right)$ e torita $\left(\mathrm{ThSiO}_{4}\right)$, dentre outros (Gascoyne, 1992). 0 tório é considerado um elemento altamente insolúvel em água devido a sua presença em minerais de difícil dissolução (resistatos), contudo, sua migração é favorecida quando complexos orgânicos/inorgânicos são formados com $\mathrm{Cl}^{-}, \mathrm{NO}_{3}^{-}, \mathrm{H}_{3} \mathrm{PO}_{4}^{0}, \mathrm{H}_{2} \mathrm{PO}_{4}^{-}, \mathrm{SO}_{4}^{2-}, \mathrm{F}^{-}, \mathrm{OH}^{-} \mathrm{e}$ $\mathrm{HPO}_{4}^{2-}$, oxalatos, citratos e EDTA (Langmuir \& Herman, 1980). 0 tório tem sido identificado como um elemento cerca de 3 a 4 vezes mais abundante que 0 urânio nas rochas crustais, devido a sua menor susceptibilidade à mobilização no ambiente supérgeno (Ivanovich \& Harmon, 1992). Isto foi também verificado para a maioria das rochas analisadas neste trabalho, tendo em vista que $64 \%$ das amostras exibiram razões Th/U entre 2 e 4 (Tab. 2).

\section{Avaliação dosimétrica das rochas}

De maneira a avaliar a potencialidade de uso das rochas analisadas para fins ornamentais, um dos parâmetros relevantes na atualidade consiste na quantificação da radioatividade devido à presença dos radioelementos $\mathrm{K}, \mathrm{U}$ e Th. Visando proceder os cálculos necessários à avaliação, as concentrações expressas em $\%$ e ppm na Tabela 2 devem ser apropriadamente convertidas para outras unidades. Em função de suas meias-vidas diferentes, a atividade de $1 \mu \mathrm{g}$ de urânio $\left({ }^{238} \mathrm{U}\right)$ corresponde a 0,746 dpm, enquanto que a de tório ${ }^{232} \mathrm{Th}$ ) corresponde a 0,246 dpm (Bonotto, 1986). Portanto, a atividade específica de $1 \mathrm{ppm}$ de ${ }^{238} \mathrm{U}$ corresponde a 12,4 Bq/ $\mathrm{kg}$, enquanto que a de 1 ppm de ${ }^{232} \mathrm{Th}$ é $4,1 \mathrm{~Bq} / \mathrm{kg}$. De acordo com WHO (2004), a razão entre ${ }^{40} \mathrm{~K}$ e K total pode ser escrita como 27,6 Bq de atividade beta (devida ao ${ }^{40} \mathrm{~K}$ ) por grama de potássio total, que é equivalente a $276 \mathrm{~Bq} / \mathrm{kg}$. Contudo, ao invés da utilização destes fatores de conversão, com o propósito de comparar os resultados obtidos neste trabalho com aqueles referidos por Anjos et al. (2005), serão adotados os seguintes valores para as atividades específicas: $1 \% \mathrm{~K}=$ $317 \mathrm{~Bq} / \mathrm{kg} ; 1 \mathrm{ppm} \mathrm{eU}=13 \mathrm{~Bq} / \mathrm{kg} ; 1$ ppm eTh = 4,08 Bq/kg. 0 emprego destes fatores de conversão permite calcular a taxa 


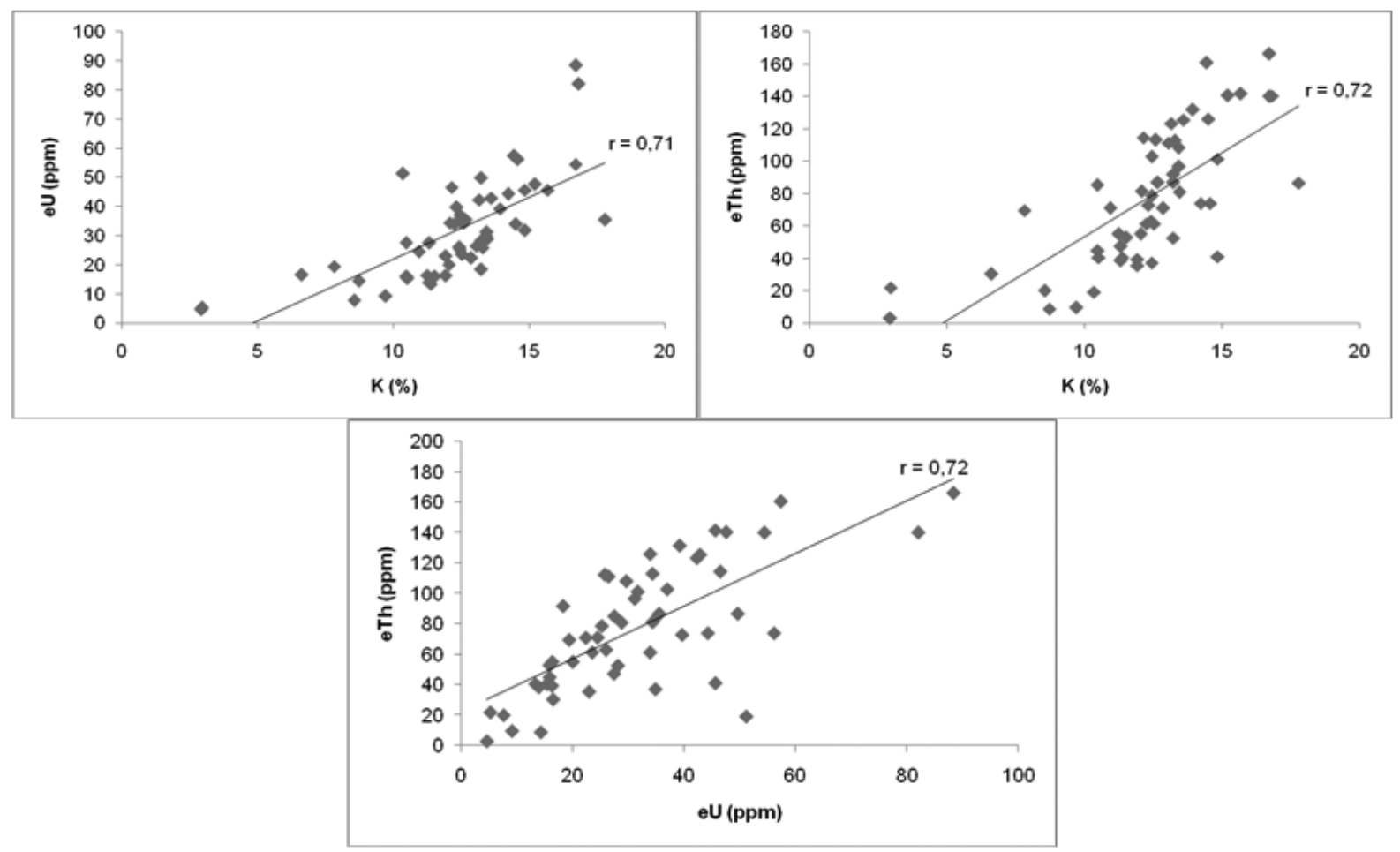

Figura 4 - Correlações das concentrações dos radioelementos naturais K, eU e eTh nas rochas do Estado de Rondônia.

de dose absorvida de radiação (T DA), em nGy/h por Bq/kg) no ar acima de $1 \mathrm{~m}$ do nível do terreno (UNSCEAR, 1993), de maneira similar ao que foi realizado por Anjos et al. (2005), isto é:

$$
T D A=0,0414 A_{K}+0,461 A_{U}+0,623 A_{T h}
$$

onde $A_{K}, A_{U}$ e $A_{T h}$ são as atividades específicas (em Bq/kg) de $\mathrm{K}$, $\mathrm{U}$ e Th, respectivamente, enquanto que os fatores de conversão de taxa de exposição gama correspondem a 0,0414, 0,461 e $0,623 \mathrm{nGy} / \mathrm{h}$ por Bq/kg para ${ }^{40} \mathrm{~K}$, ${ }^{238} \mathrm{U}$ e ${ }^{232} \mathrm{Th}$, respectivamente.

Um outro fator correspondente a 0,7 Sv/Gy, expresso por UNSCEAR (1993) e adotado por Anjos et al. (2005), pode também ser empregado para calcular a dose efetiva a partir da taxa de dose absorvida ( $T D A$ ), estando os resultados obtidos (em mSv/ano) apresentados na Tabela 3. A dose efetiva varia de 0,45 a 7,19 $\mathrm{mSv} / \mathrm{ano}$ e a análise estatística dos dados obtidos indica que os valores de dose seguem uma distribuição lognormal, conforme ilustrado na Figura 5, da mesma maneira como verificado para as distribuições das concentrações dos radioelementos (Fig. 3).

Anjos et al. (2005) apresentaram os resultados da dose efetiva para 95 tipos de granitos comercializados como rochas ornamentais. Os valores encontrados situam-se entre 0,03 e
2,2 mSv/ano, sendo que cerca de $65 \%$ das amostras exibiram valores entre 0,5 e $1 \mathrm{mSv} / \mathrm{ano}$. 0 valor modal da dose efetiva das amostras analisadas neste trabalho correspondeu a 2,7 mSv/ano, 0 qual é superior aos dados mais frequentes apresentados por Anjos et al. (2005), bem como também ligeiramente superior à média global de 2,4 mSv/ano para a dose efetiva externa devido às fontes naturais de radiação (UNSCEAR, 2000).

Tendo em vista a extensa utilização dos granitos como materiais de revestimento na construção civil, Moura et al. (2005) e Anjos et al. (2005) calcularam para suas amostras um índice ( $I$ ) de atividade (concentração gama) proposto por UNSCEAR (1993) e EC (1999), o qual facilita a derivação de taxas de dose no ar a partir de diferentes combinações dos três radioelementos. 0 índice calculado é expresso pela equação:

$$
\begin{aligned}
I=\left(C_{K} / 3000 B q / k g\right) & +\left(C_{U} / 300 B q / k g\right) \\
& +\left(C_{T h} / 200 B q / k g\right)
\end{aligned}
$$

onde $C_{K}, C_{U}$ e $C_{T h}$ são as atividades específicas (em Bq/ $\mathrm{kg}$ ) de $\mathrm{K}$, $\mathrm{U}$ e Th, respectivamente, no material de revestimento empregado em construção civil. 0 índice $I$ tem sido correlacionado à dose anual devido à radiação gama externa gerada pelo material em superfície. Conforme referido por Anjos et al. (2005), 
Tabela 3 - Resultados obtidos para a dose efetiva e índice $(I)$ de atividade (concentração gama) para as rochas do Estado de Rondônia analisadas neste trabalho.

\begin{tabular}{|c|c|c|c|c|c|}
\hline Amostra & $\begin{array}{c}\text { Dose efetiva } \\
\text { (mSv/ano) }\end{array}$ & Índice $I$ & Amostra & $\begin{array}{c}\text { Dose efetiva } \\
\text { (mSv/ano) }\end{array}$ & Índice $I$ \\
\hline \multicolumn{6}{|c|}{ Suíte Intrusiva Santo Antônio } \\
\hline MMRBP-03/01-6R & 3,59 & 4,51 & MMRBP 03/04-6R & 4,39 & 5,48 \\
\hline \multicolumn{6}{|c|}{ Suíte Intrusiva Teotônio } \\
\hline MRBP-103/2-5R & 2,36 & 3,02 & MMRBP-168/1-3R & 1,28 & 1,64 \\
\hline MMRBP-114/1-4R & 1,27 & 1,62 & MMRBP-175 & 2,02 & 2,59 \\
\hline \multicolumn{6}{|c|}{ Suíte Intrusiva Alto Candeias } \\
\hline WB-302 & 2,33 & 2,98 & WB-318A & 2,56 & 3,26 \\
\hline WB-308 & 0,45 & 0,57 & WB-319 & 2,96 & 3,78 \\
\hline \multicolumn{6}{|c|}{ Suíte Intrusiva São Lourenço-Caripunas } \\
\hline JC-261 & 2,04 & 2,60 & CR-08 & 3,16 & 4,02 \\
\hline K-1081 & 2,83 & 3,60 & CR-42 & 5,53 & 6,99 \\
\hline JC-544 & 3,40 & 4,32 & CR-48 & 3,92 & 4,93 \\
\hline JC-264 & 7,19 & 8,99 & CR-55 & 4,54 & 5,74 \\
\hline JC-566 & 2,94 & 3,73 & CR-60 & 2,66 & 3,35 \\
\hline MMRBP-50 & 2,36 & 2,98 & CR-68 & 2,13 & 2,71 \\
\hline MMRBP-180 & 6,56 & 8,20 & JWB-53 & 4,24 & 5,32 \\
\hline \multicolumn{6}{|c|}{ Suíte Intrusiva Santa Clara } \\
\hline WB-23 & 5,78 & 7,29 & 61-W-3614 & 3,76 & 4,80 \\
\hline WB-171/1 & 3,77 & 4,82 & $61-W-3610$ & 0,77 & 0,98 \\
\hline WB-14 & 3,17 & 4,07 & $60-W-4580$ & 3,51 & 4,38 \\
\hline S-1579 & 3,94 & 5,01 & $61-W-3598$ & 2,89 & 3,67 \\
\hline JR-5505 & 5,16 & 6,54 & A-2111 & 2,86 & 3,58 \\
\hline S-1573 & 3,86 & 4,91 & $61-W-3524$ & 2,43 & 3,08 \\
\hline SCL-1 & 3,97 & 5,02 & WB-37 & 1,36 & 1,72 \\
\hline $60-W-4561$ & 2,92 & 3,69 & & & \\
\hline \multicolumn{6}{|c|}{ Suíte Intrusiva Granitos Últimos de Rondônia } \\
\hline WB-185-A & 4,47 & 5,64 & SC-85-1A & 2,17 & 2,77 \\
\hline WB-186 & 3,50 & 4,42 & SC-90-3 & 4,04 & 5,13 \\
\hline WB-187 & 3,73 & 4,74 & SC-80-6 & 3,68 & 4,65 \\
\hline BF-82 & 3,19 & 4,02 & $0-2523 / 88$ & 4,63 & 5,86 \\
\hline BF-98 & 1,61 & 2,04 & $0-2564 / 81$ & 3,18 & 4,03 \\
\hline BF-101 & 3,01 & 3,70 & $0-2669 / 81$ & 5,15 & 6,52 \\
\hline SC-90-6 & 4,08 & 5,18 & B-10 & 4,38 & 5,58 \\
\hline S-0-3363 & 2,04 & 2,60 & B-204 & 4,62 & 5,86 \\
\hline
\end{tabular}

este índice estabelece um critério de dose que pode ser preliminarmente empregado como uma ferramenta útil para identificar materiais adequados para utilização como revestimento em construção civil. De acordo com EC (1999), materiais com $I \geq 6$ deveriam ser evitados, pois, poderiam gerar taxas de dose superiores a $1 \mathrm{mSv} / \mathrm{ano}$, que corresponde ao valor máximo de ex- posição à radiação recomendado para a população (UNSCEAR, 1993, 2000).

As rochas ornamentais provenientes das diferentes séries magmáticas analisadas por Moura et al. (2005) forneceram valores de $I$ entre 0,23 e 2,61, enquanto que os granitos referidos por Anjos et al. (2005) geraram valores de $I$ entre $0,04 \mathrm{e}$ 


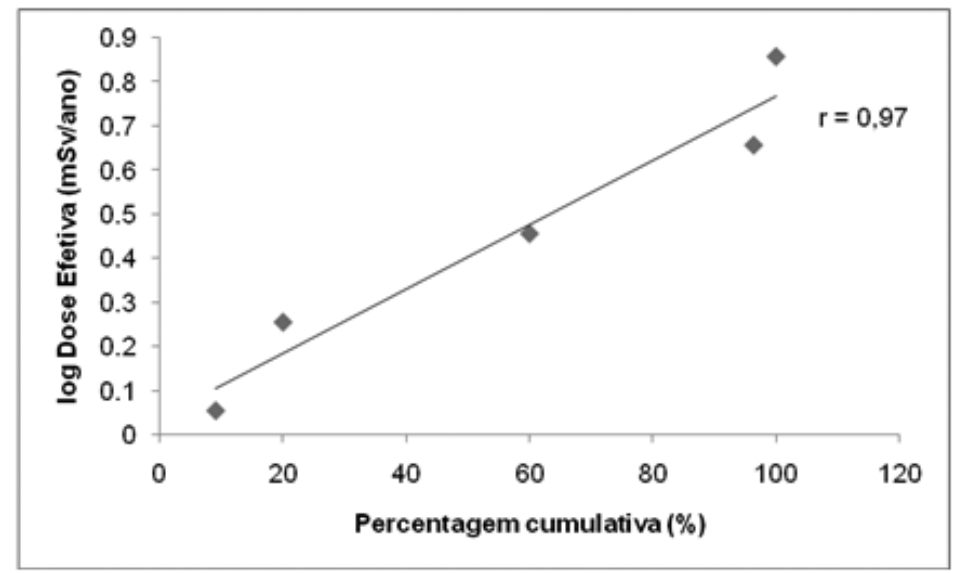

Figura 5 - Distribuição estatística dos dados de dose efetiva de radiação devida aos radioelementos naturais K, eU e eTh presentes nas rochas do Estado de Rondônia.

2,9, todos eles situados bem abaixo do máximo de 6 recomendado pela Comunidade Européia (EC, 1999). Na Tabela 3 estão apresentados os valores de $I$ calculados para as rochas analisadas neste trabalho. Segundo se verifica, para seis amostras de granitos de diferentes maciços foram determinados valores de $I>6$, sugerindo que estes materiais, do ponto de vista radiométrico, não são potencialmente adequados para emprego como revestimento em construção civil. Das 95 amostras de rochas analisadas por Anjos et al. (2005), apenas uma (charnockito) é proveniente do Estado de Rondônia, tendo sido estimado um valor de $I=0,7$ para esta amostra. Contudo, é conveniente ressaltar que os dados apresentados na Tabela 3 indicam que dentre as 55 amostras analisadas neste trabalho, apenas duas exibiram valores no intervalo $0<I<1$, que corresponde àquele onde está situado a amostra de charnockito referida por Anjos et al. (2005). Além disso, é importante também comentar que Tzortzis et al. (2003) fizeram alusão a um tipo de granito brasileiro exibindo valor de $I \sim 7,5$ e embora Anjos et al. (2005) tenham apresentado argumentos considerando a identificação errônea da amostra analisada por Tzortzis et al. (2003), os dados obtidos neste trabalho indicam a possibilidade de obtenção de $I \geq 6$ em granitos do Estado de Rondônia.

Uma utilização bastante disseminada dos granitos como rochas ornamentais consiste na confecção de tampos em pias e balcões, sobretudo em cozinhas residenciais. Isto se deve a várias propriedades adequadas como coloração, resistência e durabilidade, porém, a presença de urânio em sua composição mineralógica pode contribuir com a produção do gás nobre ${ }^{222} \mathrm{Rn}$ que é um dos descendentes do ${ }^{238} \mathrm{U}$ na série de decaimento $4 n+2$ (Adams \& Gasparini, 1970). Estudos envolvendo a exalação de
${ }^{222} \mathrm{Rn}$ de vários tipos de granitos têm sido conduzidos por diferentes autores, a exemplo de Al-Jarallah (2001) e Chyi (2008). Os resultados apresentados por Chyi (2008) indicaram que os valores da atividade de ${ }^{222} \mathrm{Rn}$ situam-se abaixo do máximo recomendado por USEPA (2007). Contudo, não há ainda dados enfocando a exalação deste gás por parte das rochas analisadas neste trabalho, constituindo este tópico uma possibilidade de investigação futura que pode introduzir avanços importantes na avaliação da potencialidade de uso dos granitos do Estado de Rondônia para finalidades de revestimento.

\section{CONSIDERAÇÕES FINAIS}

Este trabalho permitiu avaliar a concentração dos radioelementos naturais $\mathrm{K}$, eU e eTh em granitos provenientes do Estado de Rondônia no Brasil. A área estudada faz parte do Cráton Amazônico, cuja compartimentação e evolução geotectônica têm sido avaliadas por diferentes modelos publicados na literatura especializada. A análise radiométrica foi conduzida por espectrometria gama com detector de cintilação de Nal(TI), tendo sido o sistema calibrado por intermédio de padrões internacionais adquiridos junto ao NBL (New Brunswick Laboratory) do U.S. Department of Energy, Argonne, Illinois. Os resultados foram obtidos para um total de 55 amostras coletadas em diferentes suítes, possibilitando a determinação da taxa de dose absorvida de radiação, que é um parâmetro importante na avaliação da potencialidade de uso das rochas analisadas para fins ornamentais. A dose efetiva calculada variou de 0,45 a 7,19 mSv/ano e a análise estatística dos dados obtidos indicou que os valores de dose seguem uma distribuição lognormal, cujo valor modal correspondeu a 2,7 mSv/ano, o qual é ligeiramente superior à média global 
de 2,4 mSv/ano para a dose efetiva externa devido às fontes naturais de radiação. Para seis amostras (0-2669/81, MMRBP-180, CR-42, JC-264, JR-5505 e WB-23) foram determinados valores superiores a 6 para 0 índice de atividade gama, os quais sugerem que, do ponto de vista radiométrico, as rochas não são potencialmente adequadas para emprego como material de revestimento em construção civil.

\section{AGRADECIMENTOS}

J.S.B. agradece à FAPESP (Fundação de Amparo à Pesquisa do Estado de São Paulo - Processos 1989/0308 e 2000/08033-5) pelo apoio financeiro para a realização desta pesquisa. E.G.S. agradece ao CNPq (Conselho Nacional de Desenvolvimento Científico e Tecnológico - Processo 151213/2007-0) pela bolsa de estudos concedida. Os autores agradecem a dois revisores anônimos que contribuiram para a melhoria do manuscrito.

\section{REFERÊNCIAS}

ABIROCHAS (ASSOCIAÇÃO BRASILEIRA DA INDÚSTRIA DE ROCHAS ORNAMENTAIS). 2008. Catálogo brasileiro de rochas ornamentais. Disponivel em: <http://www.abirochas.com.br> . Acesso em: 24 out. 2008.

ADAMS JAS \& GASPARINI P. 1970. Gamma ray spectrometry of rocks. Elsevier, Amsterdam, 295 pp.

ADAMS JAS, OSMOND JK \& ROGERS JJW. 1959. The geochemistry of thorium and uranium. In: AHRENS LH, PRESS F, RANKAMA K \& RUNCORN SK (Eds.). Physics and Chemistry of the Earth Series, v. 3. Pergamon, London, $299 \mathrm{pp}$.

AL-JARALLAH M. 2001. Radon exhalation from granites used in Saudi Arabia. Journal of Environmental Radioactivity, 53: 91-98.

ALMEIDA FFM de. 1978. A evolução dos Crátons Amazônico e do São Francisco comparada com a de seus homólogos do hemisfério Norte. In: Congr. Bras. Geol., 30: 1978, Recife. Anais... Recife: SBG, 1978. v. 6, p. 2393-2407.

ANJOS RM, VEIGA R, SOARES T, SANTOS AMA, AGUIAR JG, FRASCÁ MHBO, BRAGE JAP, UZÊDA D, MANGIA L, FACURE A, MOSQUERA B, CARVALHO C \& GOMES PRS. 2005. Natural radionuclide distribution in Brazilian commercial granites. Radiation Measurements, 39: 245-253.

BETTENCOURT JS \& KAEDEI M. 1984. Reconhecimento dos granitos rapakivi (senso stricto) da região do rio Caripunas, Rondônia. In: Simp. Amazônico, 2: 1984, Manaus. Atas... Manaus: SBG-NN, 1984. p. 271285.

BETTENCOURT JS, LEITE JÚNIOR WB, PAYOLLA BL \& MONTANHEIRO TJ. 1991. Contribuição à geoquímica, petrologia e metalogenia dos granitos anorogênicos de Rondônia no intervalo de 1270 a $950 \mathrm{Ma}$. Relatório Técnico, FAPESP, São Paulo, 169 pp.
BETTENCOURT JS, LEITE JÚNIOR WB, PAYOLLA BL, SCANDOLARA JE, MUZZOLON R \& VIAN JAJ. 1997. The rapakivi granites of the Rondônia Tin Province, Northern Brazil. In: Int. Symp. Granites and Associated Mineralizations, 2: 1997, Salvador. Excursions Guide, Salvador: CBPM/SGM, 1997. p. 3-31.

BETTENCOURT JS, TOSDAL RM, LEITE JÚNIOR WB \& PAYOLLA BL. 1999. Mesoproterozoic rapakivi granites of the Rondônia Tin Province, Southwestern border of the Amazonian Craton, Brazil: I. Reconnaissance $\mathrm{U}-\mathrm{Pb}$ geochronology and regional implications. Precambrian Research, 95: 41-67.

BONOTTO DM. 1986. Aplicações hidrogeoquímicas dos isótopos naturais das séries do U (4n+2) e Th (4n) no Morro do Ferro, Poços de Caldas (MG). Tese de doutorado, IAG - USP, São Paulo, 378 pp.

BROWN H \& SILVER LT. 1955. The possibilities of obtaining long-term supplies of uranium, thorium and other substances of uranium from igneous rocks. In: Conf. On the Peaceful Uses of Atomic Energy, 1955 Geneva. Proc... Geneva: IAEA (International Atomic Energy Agency) p. $91-95$.

CHIODI FILHO C. 1997. Guias prospectivos para mineralizações em rochas granitóides. Estudos e documentos, 34. MCT/CNPq/CETEM. Rio de Janeiro. 64 pp.

CHIOZZI P, DE FELICE P, FAZIO A, PASQUALE V \& VERDOYA M. 2000. Laboratory application of Nal(TI) $\gamma$-ray spectrometry to studies of natural radioactivity in geophysics. Applied Radiation and Isotopes, 53: 127-132.

CHYI LL. 2008. Radon testing of various countertop materials - Final report. Tech. Report, The University of Akron. 14 pp.

CURRIE LA. 1968. Limits for qualitative detection and quantitative determination. Analytical Chemistry, 40: 586-593.

DALRYMPLE GB \& LANPHERE M. 1969. Potassium-argon dating Principles, techniques and applications to geochronology. Freeman, San Francisco, 258 pp.

DUARTE CR \& BONOTTO DM. 2000. Calibração em energia e concentração de espectrômetro gama para análise de U, Th e K. Geociências, 19: 313-319.

EC. 1999. European Commission report on radiological protection principles concerning the natural radioactivity of building materials. Radiation Protection, v. 112. $16 \mathrm{pp}$.

EL-NABY HHA \& SALEH GM. 2003. Radioelement distributions in the Proterozoic granites and associated pegmatites of Gabal El Fereyid area, Southeastern Desert, Egypt. Applied Radiation and Isotopes, 59(4): 289-299.

GABELMAN J. 1977. Migration of $\mathrm{U}$ and Th exploration significance. Study in Geology N 3. AAPG. 168 pp. 
GASCOYNE M. 1992. Geochemistry of the actinides and their daughters. In: IVANOVICH M \& HARMON RS (Eds.). Uranium-series Disequilibrium: Applications to Earth, Marine, and Environmental Sciences. Clarendon Press, Oxford, p. 34-62.

GAVSHIN VM, SHCHERBOV BL, BOBROV VA, SOLOTCHINA EP, SUKHORUKOV FV \& MELGUNOV MS. 1997. Behavior of minor elements in the process of formation of a weathering profile on granites. Geologiya I Geofizika, 38(7): 1228-1239.

IVANOVICH M \& HARMON RS. 1992. Uranium-series Disequilibrium: Applications to Earth, Marine, and Environmental Sciences. $2^{\text {nd }}$ edition. Oxford Univ. Press, Oxford, 910 pp.

KILLEEN PG. 1979. Gamma-ray spectrometric methods in uranium exploration - application and interpretation. In: HOOD PJ (Ed.). Geophysics and Geochemistry in the Search for Metallic Ores, Geological Survey of Canada, p. 163-229 (Economic Geology Report, 31).

KUMAR PS \& REDDY GK. 2004. Radioelements and heat production of an exposed Archaean crustal cross-section, Dharwar craton, south India. Earth and Planetary Science Letters, 224(3-4): 309-324.

LANGMUIR D \& HERMAN JS. 1980. The mobility of thorium in natural waters at low temperatures. Geochimica et Cosmochimica Acta, 44: 1753-1766.

LARSEN ES \& PHAIR G. 1954. The distribution of uranium and thorium in igneous rocks. In: FAUL H (Ed.). Uranium and thorium. John Wiley \& Sons, New York, p. 75-89.

LEITE JÚNIOR WB. 2002. A Suíte Intrusiva Santa Clara (RO) e a mineralização primária polimetálica (Sn, W, Nb, Ta, Zn, Cu e Pb) associada. Tese de doutorado, IG-USP, São Paulo, 305 pp.

LEITE JÚNIOR WB, OLIVEIRA RCB, TAMBORIM DAR, PAYOLLA BL \& BETTENCOURT JS. 2005. Geoquímica dos topázios granitos do stock Palanqueta, mina Bom Futuro, Rondônia: considerações preliminares. In: Congr. Bras. Geoquímica, 10: 2005, Porto de Galinhas. Anais... Porto de Galinhas: SBGq, 2005. CD-ROM, 4 pp.

MOREIRA-NORDEMANN LM. 1977. Étude de la vitesse d'altération des roches au moyen de l'uranium utilisé comme traceur naturel. Application à deux bassins du nord-est du Brésil. Thèse de Doctorat d'État, Université Pierre et Marie Curie, Paris, 162 pp.

MOURA CL, ARTUR AC \& BONOTTO DM. 2005. Radioatividade natural em rochas ornamentais provenientes de diferentes séries magmáticas. In: Congr. Int. Rochas Ornamentais, 1: 2005, Guarapari. CD-ROM... Guarapari: CETEM, 2005, 6 pp.

OSMOND JK \& COWART JB. 1976. The theory and uses of natural uranium isotopic variations in hydrology. Atomic Energy Review, 14: 621679.

PAYOLLA BL. 1994. As rochas graníticas e sieníticas das cachoeiras Teotônio e Santo Antônio, rio Madeira, Porto Velho, Rondônia: geologia, petrografia e geoquímica. Dissertação de Mestrado, Instituto de Geociências, Universidade de Brasília, Brasília, 145 pp.

PICCIOTTO EF. 1950. Distribution de la radioactivité dans les roches eruptives. Soc. Belg. Geol. Bull., 59: 170-178.

QUADROS NLES \& RIZZOTTO GJ. 2007. Geologia e Recursos Minerais do Estado de Rondônia - Sistema de Informações Geográficas. Texto Explicativo do Mapa Geológico e de Recursos Minerais do Estado de Rondônia. Programa Geologia do Brasil, CPRM, Porto Velho, 153 p.

ROBB LJ, MEYER FM, FERRAZ MF \& DRENNAN GK. 1990. The distribution of radioelements in Archaean granites of the Kaapvaal Craton, with implications for the source of uranium in the Witwatersrand Basin. South African Journal of Geology, 93(1): 5-40.

ROUBAULT M. 1958. Géologie de I'Uranium. Masson, Paris, 462 pp.

SALAS HT, NALINI HA \& MENDES JC. 2003. Radioatividade em rochas graníticas ornamentais do Brasil. In: Simp. Rochas Ornamentais do Nordeste, 4: 2003, Fortaleza. Anais... Fortaleza: CETEM, 2003. p. 68-73.

SANTOS JOS. 2003. Geotectônica dos escudos das Guianas e BrasilCentral. In: BIZZI LA, SCHOBBENHAUS C, VIDOTTI RM \& GONÇALVES JH (Eds.). Geologia, Tectônica e Recursos Minerais do Brasil. CPRM, Brasília, p. 169-226.

SCHEEPERS R. 2000. Granites of the Saldania mobile belt, South Africa: radioelements and $P$ as discriminators applied to metallogeny. Journal of Geochemical Exploration, 68(1-2): 69-86.

SEIMBILLEF, ZUDDAS P \& MICHARD G. 1998. Granite-hydrothermal interaction: a simultaneous estimation of the mineral dissolution rate based on the isotopic doping technique. Earth and Planetary Science Letters, 157(3-4): 183-191.

SHARMA PV. 1986. Geophysical Methods in Geology. Elsevier, New York, $442 \mathrm{pp}$.

SPEER JA, SOLBERG TN \& BECKER SW. 1981. Petrography of the uranium-bearing minerals of the Liberty Hill pluton, South Carolina: phase assemblages and migration of uranium in granitoid rocks. Economic Geology, 76: 2162-2175.

TIEH TT \& LEDGER EB. 1981. Fission track study of uranium in two granites of central Texas. Contributions to Mineralogy and Petrology, 76 : $12-16$.

TZORTZIS M, TSERTOS H, CHRISTOFIDES S \& CHRISTODOULIDES G. 2003. Gamma radiation measurements and dose rates in commerciallyused natural tiling rocks (granites). Journal of Environmental Radioactivity, 70: 223-235.

UNSCEAR. 1993. Sources and effects of ionizing radiation. United Nations Scientific Committee on the Effects of Atomic Radiation. United Nations, New York. 17 pp. 
UNSCEAR. 2000. Sources and effects of ionizing radiation. United Nations Scientific Committee on the Effects of Atomic Radiation. United Nations, New York. 17 pp.

USEPA (U.S. Environmental Protection Agency). 2007. A citizen's guide to radon: the guide to protecting yourself and your family from radon. Indoor Environments Division (6609J), EPA 402-K-07-009, 16 pp.

WEIJDEN CH \& WEIJDEN RD. 1995. Mobility of major, minor and some redox-sensitive trace elements and rare-earth elements during weathering of four granitoids in central Portugal. Chemical Geology, 125(3-4): $149-167$.
WARD SH. 1981. Gamma-ray spectrometry in geologic mapping and uranium exploration. Economic Geology, $75^{\text {th }}$ Anniversary Volume: 840-849.

WHO (World Health Organization). 2004. Guidelines for drinking water quality: radiological aspects. Disponível em: $<$ http:www.who.int/water_sanitation_health/dwq/gdwq3/en/>. Acesso em: 16 nov. 2004.

YOUNG HD. 1962. Statistical treatment of experimental data. McGraw Hill, New York, 172 pp.

\section{NOTAS SOBRE OS AUTORES}

Daniel Marcos Bonotto. Possui graduação em Física pela Universidade Estadual Paulista Júlio de Mesquita Filho (1978), Mestrado em Geofísica pela Universidade de São Paulo (1982) e Doutorado em Geofísica pela Universidade de São Paulo (1986). Realizou Livre-Docência em Geoquímica (1997) e atualmente é Professor Adjunto da Universidade Estadual Paulista Júlio de Mesquita Filho. Tem experiência na área de Geociências, com ênfase em Geofísica Nuclear e Geoquímica Isotópica, atuando principalmente nos seguintes temas: radioatividade natural, análises hidroquímicas, águas superficiais e subterrâneas. Tem coordenado 0 Grupo de Pesquisa cadastrado no CNPq "Hidroquímica e Radioatividade na Geosfera".

Washington Barbosa Leite Júnior. Possui graduação em Geologia pela Universidade Estadual Paulista Júlio de Mesquita Filho (1980), Mestrado em Geociências (Recursos Minerais e Hidrogeologia) pela Universidade de São Paulo (1992) e Doutorado em Geociências (Recursos Minerais e Hidrogeologia) pela Universidade de São Paulo (2002). Atualmente é Professor Assistente Doutor da Universidade Estadual Paulista Júlio de Mesquita Filho. Tem experiência na área de Geociências, com ênfase em Metalogenia, atuando principalmente nos seguintes temas: geologia do sudoeste do Cráton Amazônico, granitos, estanho, depósitos minerais, petrogênese e evolução crustal no Estado de Rondônia.

Bruno Leonelo Payolla. Possui graduação em Geologia pela Universidade Estadual Paulista Júlio de Mesquita Filho (1980) e Mestrado em Geologia pelo Instituto de Geociências da Universidade de Brasília (1994). Atualmente é funcionário da ELETRONORTE-Centrais Elétricas do Norte do Brasil S.A. Tem experiência e interesse na área de Geociências, com ênfase em Evolução Crustal da Borda Sudoeste do Cráton Amazônico, Evolução e Metalogenia dos Granitóides da Província Estanífera de Rondônia e na área de Geologia Ambiental, com ênfase em Estudos de Impacto Ambiental de Usinas Hidrelétricas, Usinas Termelétricas e Linhas de Transmissão de Energia e Geomorfologia Fluvial.

Jorge da Silva Bettencourt. Graduado em Geologia pela Universidade de São Paulo (1961), Doutorado (1972) e Livre-Docente (1992) pela Universidade de São Paulo. É Professor Titular permissionário do Instituto de Geociências da Universidade de São Paulo, desde 2000. Possui experiência nas áreas de exploração mineral e modelos de depósitos minerais, atuando como geólogo de exploração mineral e como consultor. 0 interesse atual em pesquisa está mais dirigido à metalogenia e à exploração mineral, tendo como foco os temas: Cráton Amazônico e Bacia do São Francisco, evolução crustal Proterozóica e modelamento metalogenético de depósitos minerais utilizando isótopos estáveis e inclusões fluídas.

Ene Glória da Silveira. Possui graduação em Geologia pela Universidade Federal do Ceará (1981), Mestrado em Geociências e Meio Ambiente pela Universidade Estadual Paulista Júlio de Mesquita Filho (1992) e Doutorado em Geociências e Meio Ambiente pela Universidade Estadual Paulista Júlio de Mesquita Filho (1998). Atualmente é Professor Associado da Universidade Federal de Rondônia (UNIR), onde exerceu o cargo de Reitor por dois mandatos. Tem experiência na área de Geociências, com ênfase em Geologia Regional, atuando principalmente no seguinte tema: mercúrio no rio Madeira. 